\title{
Pivot to Asia: inflammatory bowel disease burden
}

\author{
Prashant Singh ${ }^{1}$, Ashwin Ananthakrishnan ${ }^{2}$, Vineet Ahuja ${ }^{3}$ \\ ${ }^{1}$ Division of Gastroenterology, Beth Israel Deaconess Medical Center, Boston, MA, ${ }^{2}$ Division of Gastroenterology, Massachusetts General \\ Hospital, Boston, MA, USA, ${ }^{3}$ Department of Gastroenterology, All India Institute of Medical Sciences, New Delhi, India
}

Inflammatory bowel disease (IBD) is a chronic, relapsing, inflammatory disorder of the gastrointestinal tract, and includes UC and CD. IBD results from a combination of genetic susceptibility, environmental exposure, and dysregulated response to intestinal microbiota. ${ }^{1}$ The incidence and prevalence of IBD has been increasing worldwide and appears to be highest in North America and Europe. ${ }^{1}$ Despite its previously low incidence, Asia has experienced a significant increase in IBD in the past two decades, while Europe has seen a plateau or even a decreasing incidence. ${ }^{1}$ The highest incidence of IBD in Asia has been reported from East and South Asian countries of China, Japan, South Korea, and India. ${ }^{1}$ With the plateau of IBD incidence in several Western countries and rising incidence in Asian countries, the geographic landscape of IBD may be rapidly changing.

In a systematic review on the epidemiology of IBD, Molodecky et al. ${ }^{2}$ reported the United States and Sweden among the countries with the highest occurrence of IBD. They also reported China, Japan, South Korea, and India among the countries with the lowest occurrence of IBD. ${ }^{2}$ Despite the data on the prevalence and incidence of UC and CD, the estimated current disease burden of these diseases in various Asian countries in comparison to Western countries is not clear. We aimed to estimate the disease burden of UC and CD in these six countries, with 2010 as the reference year.

We searched PubMed with keywords "Ulcerative colitis," "Crohn's disease" or "Inflammatory bowel disease," and "incidence" or "prevalence." Each was cross-referenced with the

Received October 21, 2016. Revised November 30, 2016.

Accepted December 2, 2016.

Correspondence to Vineet Ahuja, Department of Gastroenterology, All

India Institute of Medical Sciences, New Delhi 110029, India. Tel: +91-11-

26588500, Fax: +91-11-26588641, E-mail: vineet.aiims@gmail.com

Financial support: None. Conflict of interest: None. six countries mentioned above. The study with the most recent data on prevalence and incidence of CD and/or UC was selected for each country. Wherever possible, a populationbased study was selected to estimate both prevalence and incidence. If population-based data were not available, the latest hospital-based study was used. Prevalence and annual incidence was derived from each of the selected studies. ${ }^{3-12}$ The census data from each country were used to estimate their national population in the year of the prevalence study. Available data on prevalence was superimposed on the national population at the time of the study to estimate the disease burden of CD or UC. ${ }^{3-12}$ Data on incidence rates were used to calculate the new cases of UC or CD since the last prevalence study. ${ }^{7-9,12}$ For most of the selected countries, the rate of increase in annual incidence of UC and/or CD is not known; thus, to maintain uniformity, the incidence was assumed to be stable since last reported. The most current annual incidence rates available were superimposed on the national population at the time of the latest prevalence study to calculate the number of patients newly diagnosed with UC or CD every year. ${ }^{3-12}$ This was then multiplied by the number of years between the last prevalence study and 2010 to calculate the newly diagnosed cases of CD or UC between the last prevalence calculation and 2010. The total national disease burden of UC and CD in 2010 was calculated by adding this number of newly diagnosed cases of CD or UC to the baseline national disease burden at the time of the latest prevalence study.

The estimated disease burden in 2010 for India was 1.1 million patients with UC, as compared to 0.8 million in the United States and 0.5 million in China. The estimated burden of UC patients in the other above mentioned countries is detailed in Table 1.

In 2010, the estimated number of patients with $\mathrm{CD}$ in the

\footnotetext{
๑ Copyright 2017. Korean Association for the Study of Intestinal Diseases. All rights reserved.

This is an Open Access article distributed under the terms of the Creative Commons Attribution Non-Commercial License (http://creativecommons.org/licenses/by-nc/4.0)

which permits unrestricted non-commercial use, distribution, and reproduction in any medium, provided the original work is properly cited.
} 
Table 1. Absolute Number of IBD Cases in Various Regions of the World (Calculated for 2010)

\begin{tabular}{lcccccccrr}
\hline \multicolumn{1}{c}{ Country } & Year & $\begin{array}{c}\text { Population at } \\
\text { the time of } \\
\text { prevalence study }\end{array}$ & $\begin{array}{c}\text { UC } \\
\text { prevalence }\end{array}$ & $\begin{array}{c}\text { UC } \\
\text { incidence }^{\text {a }}\end{array}$ & $\begin{array}{c}\text { UC disease } \\
\text { burden in } \\
\mathbf{2 0 1 0}\end{array}$ & $\begin{array}{c}\text { CD } \\
\text { prevalence }^{\text {a }}\end{array}$ & $\begin{array}{c}\text { CD } \\
\text { incidence }^{\text {a }}\end{array}$ & $\begin{array}{c}\text { CD disease } \\
\text { burden in } \\
\mathbf{2 0 1 0}\end{array}$ & $\begin{array}{c}\text { IBD disease } \\
\text { burden in } \\
\mathbf{2 0 1 0}\end{array}$ \\
\hline South Korea & 2005 & $47,278,951$ & $30.87^{3}$ & $3.08^{3}$ & $21,875.97$ & $11.24^{3}$ & $1.34^{3}$ & $8,481.80$ & $30,357.77$ \\
Japan & 2005 & $127,768,000$ & $63.60^{4}$ & $1.95^{9}$ & $93,717.83$ & $21.20^{4}$ & $1.20^{11}$ & $34,752.90$ & $128,471.90$ \\
Sweden & 2010 & $9,415,570$ & $350^{5}$ & N/A & $32,835.00$ & $190^{5}$ & N/A & $18,299.00$ & $51,143.90$ \\
USA & 2010 & $308,745,538$ & $286.3^{6}$ & N/A & $883,938.48$ & $246.7^{6}$ & N/A & $761,675.24$ & $1,645,621.62$ \\
India & 1999 & $1,016,118,000$ & $44.3^{7}$ & $6.02^{7}$ & $1,123,013.61$ & - & - & $280,753.00$ & $1,403,766.61$ \\
China & 2006 & $1,311,400,000$ & $26.5^{8}$ & $2.05^{8}$ & $455,055.80$ & $2.7^{10}$ & $1.09^{12}$ & $92,584.84$ & $547,641.73$ \\
\hline
\end{tabular}

${ }^{a}$ Number of patients per 100,000 people.

$N / A$, as the prevalence study is from 2010, incidence data are not needed to estimate disease burden.

United States was about 0.8 million. This is much higher compared to the CD burden in China (0.09 million), Japan (0.03 million), Sweden (0.02 million), and South Korea (0.01 million). There are no prevalence and/or incidence studies on CD in India, but hospital-based studies have shown that for every four cases of $\mathrm{UC}$, at least one CD case is detected in India. ${ }^{13,14}$ Thus, the presumed burden of CD in India in 2010 was about 0.3 million.

Among the six countries studied, the United States appears to have the highest burden of IBD patients (1.6 million), closely followed by 1.4 million in India. The disease burden of other countries is summarized in Table 1.

Our analysis shows that despite being considered countries with low occurrence of UC and CD, many Asian countries have substantially higher numbers of IBD patients compared to Western countries considered to have high occurrence of IBD. The prevalence of UC in India (44.3 per $100,000)$ is much lower than that in the United States (286.3 per 100,000) or Sweden (350 per 100,000). ${ }^{5-7}$ Moreover, the incidence of UC in India (6.02 per 100,000) is much lower than the UC incidence in United States (8.8 per 100,000) and Sweden (20 per 100,000) ${ }^{7,15,16}$ However, because of its population size, India has a much higher disease burden of UC compared to other countries with much higher incidence and prevalence of UC, including the United States and Sweden. The disease burden of CD appears to be highest in the United States, with about 0.8 million CD patients. We estimate that there are about 0.3 million CD patients in India. Interestingly, despite much lower CD incidence and prevalence compared to Sweden, China, and Japan have a burden of CD almost 4.5 times and 3 times higher, respectively.

Thus, India has the highest burden of IBD in Asia and one of the highest in the world. Despite the low prevalence and incidence of IBD, Asian countries might have a significantly higher burden of IBD patients compared to Western countries. While the incidence and prevalence of IBD have stabilized in North America and Europe, both continue to rise in low-incidence regions such as Eastern Europe, Africa, and Eastern and Southern Asia. ${ }^{1,16}$ This changing epidemiology of IBD over time and geography suggests that environmental factors play a major role in pathogenesis. Changes in lifestyle in developing countries have resulted in more "Westernized" diets, leading to higher consumption of fatty acids, refined sugars, and fast food and less consumption of fruits, vegetables, and fiber. ${ }^{17-19}$ Urbanization of societies leading to improved hygiene status, change in microbial exposure, and antibiotic use could also be contributing to the pathogenesis. ${ }^{1,17,18}$ In addition, the susceptibility genes for IBD appear to be different among Western and Asian countries. ${ }^{18}$ This rising incidence of IBD in developing countries gives us a novel chance to explore the genetic and environmental factors underlying the pathogenesis of IBD.

Increasing disease burden of IBD among developing countries raises several concerns. First, it is unclear whether healthcare systems in these countries are prepared to deal with the burden. Clearly, the disease burden of IBD in several Asian countries is much higher than we expected, and in many of these regions, IBD is still considered rare, leading to frequent underdiagnosis or misdiagnosis. ${ }^{1,17,18}$ Epidemiological studies from the majority of developing countries are lacking, making it difficult to estimate the exact burden of UC and/or CD in several Asian countries. Well-designed pannational epidemiological studies covering both rural and urban settings, along with regions with varied ethnicities, are much needed. There is also a need to increase awareness among healthcare providers on the appropriate diagnosis of IBD in countries with high background prevalence of infections, especially tuberculosis. Use of biologics in developing 
countries is limited due to high cost and high prevalence of infections such as tuberculosis. ${ }^{18}$ The major significance of the awareness of the high disease burden of IBD in India is that it outlines the urgent necessity for an adequate number of health care providers, facilities for diagnosis and treatment of a massive patient load, and sensitization of health care agencies to promote research on cost-effective methods of therapy. Despite one of the highest disease burdens of IBD in the world, India has one of the most deficient public health insurance systems in Asia. ${ }^{19}$ As most Indian patients end up paying for their medical expense, only a minority of patients who need expensive therapies such as biologics can afford them. ${ }^{19}$

Our study also had several limitations. First, the disease burden in our study is only a close estimation of the exact number, as we have used prevalence and incidence rates in our calculation that are based on studies limited to a particular geographic region, and are not pan-national. Second, we used the last available incidence rates for our calculation, which might have led to underestimation of the disease burden, given the fact that available studies suggest rising incidence of IBD in some Asian countries. However, recent studies from South Korea suggest that the incidence might also be plateauing in other Asian countries. In addition, several prevalence and incidence values have been estimated from hospital-based studies. For example, there are no population-based prevalence studies on UC from China; thus, we used the hospital-based study by Chow et al. ${ }^{8}$ In addition, the number of new cases diagnosed since the last prevalence study was calculated used the baseline population at the time of prevalence calculation, and did not take into account population growth since then. Thus, the disease burden estimation in countries such as India, where the population is growing rapidly, is likely an underestimation.

In conclusion, the disease burden of IBD in developing countries is much higher than in the developed world. It is imperative that their healthcare systems be prepared for this challenge.

\section{REFERENCES}

1. Ng WK, Wong SH, Ng SC. Changing epidemiological trends of inflammatory bowel disease in Asia. Intest Res 2016;14:111119.

2. Molodecky NA, Soon IS, Rabi DM, et al. Increasing incidence and prevalence of the inflammatory bowel diseases with time, based on systematic review. Gastroenterology 2012;142:46-54. e42.
3. Yang SK, Yun S, Kim JH, et al. Epidemiology of inflammatory bowel disease in the Songpa-Kangdong district, Seoul, Korea, 1986-2005: a KASID study. Inflamm Bowel Dis 2008;14:542549.

4. Asakura K, Nishiwaki Y, Inoue N, Hibi T, Watanabe M, Takebayashi T. Prevalence of ulcerative colitis and Crohn's disease in Japan. J Gastroenterol 2009;44:659-665.

5. Büsch K, Ludvigsson JF, Ekström-Smedby K, Ekbom A, Askling J, Neovius M. Nationwide prevalence of inflammatory bowel disease in Sweden: a population-based register study. Aliment Pharmacol Ther 2014;39:57-68.

6. Shivashankar R, Tremaine WJ, Harmsen WS, Zinsmeister A, Loftus E. Updated incidence and prevalence of Crohn's disease and ulcerative colitis in Olmsted County, Minnesota (19702010). Am J Gastroenterol 2014;109(Suppl 2):S449.

7. Sood A, Midha V, Sood N, Bhatia AS, Avasthi G. Incidence and prevalence of ulcerative colitis in Punjab, north India. Gut 2003;52:1587-1590.

8. Chow DK, Leong RW, Tsoi KK, et al. Long-term follow-up of ulcerative colitis in the Chinese population. Am J Gastroenterol 2009;104:647-654.

9. Morita N, Toki S, Hirohashi T, et al. Incidence and prevalence of inflammatory bowel disease in Japan: nationwide epidemiological survey during the year 1991. J Gastroenterol 1995;30 Suppl 8:1-4.

10. Lok KH, Hung HG, Ng CH, Li KK, Li KF, Szeto ML. The epidemiology and clinical characteristics of Crohn's disease in the Hong Kong Chinese population: experiences from a regional hospital. Hong Kong Med J 2007;13:436-441.

11. Yao T, Matsui T, Hiwatashi N. Crohn's disease in Japan: diagnostic criteria and epidemiology. Dis Colon Rectum 2000;43(10 Suppl):S85-S93

12. Zeng Z, Zhu Z, Yang Y, et al. Incidence and clinical characteristics of inflammatory bowel disease in a developed region of Guangdong Province, China: a prospective population-based study. J Gastroenterol Hepatol 2013;28:1148-1153.

13. Ramakrishna BS, Makharia GK, Ahuja V, et al. Indian Society of Gastroenterology consensus statements on Crohn's disease in India. Indian J Gastroenterol 2015;34:3-22.

14. Ahuja V, Tandon RK. Inflammatory bowel disease: the Indian augury. Indian J Gastroenterol 2012;31:294-296.

15. Loftus CG, Loftus EV Jr, Harmsen WS, et al. Update on the incidence and prevalence of Crohn's disease and ulcerative colitis in Olmsted County, Minnesota, 1940-2000. Inflamm Bowel Dis 2007;13:254-261. 
16. Sjöberg D, Holmström T, Larsson M, et al. Incidence and natural history of ulcerative colitis in the Uppsala Region of Sweden 2005-2009: results from the IBD cohort of the Uppsala Region (ICURE). J Crohns Colitis 2013;7:e351-e357.

17. Ng SC. Epidemiology of inflammatory bowel disease: focus on Asia. Best Pract Res Clin Gastroenterol 2014;28:363-372.
18. Prideaux L, Kamm MA, De Cruz PP, Chan FK, Ng SC. Inflammatory bowel disease in Asia: a systematic review. J Gastroenterol Hepatol 2012;27:1266-1280.

19. Wei SC. Differences in the public medical insurance systems for inflammatory bowel disease treatment in Asian countries. Intest Res 2016;14:218-223. 